\title{
Laparoscopic liver resection: lessons learnt after 100 cases
}

\author{
Fiona KM Chan *, KC Cheng, YP Yeung
}

\section{A B S T R A C T}

Objective: To share our institutional experience in laparoscopic liver resection and our learning curve after the first 100 cases of laparoscopic liver resection.

Design: Case series with internal comparison.

Setting: A regional hospital in Hong Kong.

Patients: Our institution started performing laparoscopic liver resection since 2006. All patients who underwent laparoscopic liver resections from March 2006 to October 2012 were identified in a prospectively collected database. The demographic data and operative outcomes of these patients were extracted, and results of the early (from March 2006 to May 2010) and late (from June 2010 to October 2012) study periods were compared.

Results: Between March 2006 and October 2012, 100 laparoscopic liver resections were performed for 98 patients in the Department of Surgery, Kwong Wah Hospital, Hong Kong. They were 69 (70\%) males and 29 (30\%) females, and the median age was 65 years.
This article was published on $11 \mathrm{Apr}$ 2014 at www.hkmj.org. metastases $(\mathrm{n}=14)$, intrahepatic cholangiocarcinoma $(n=4)$, and benign disease $(n=10)$. There were more anatomical resections, major hepatectomies as well as resections of more anatomically challenging right-sided and posterosuperior lesions in the late versus the early period; however, operative outcomes remained comparable in both periods.

Conclusion: Laparoscopic hepatectomies are feasible with growing experience. Bearing in mind the diversity in the level of operative techniques with various types of laparoscopic liver resections, more experience is needed to overcome the learning curve.

\section{Hong Kong Med J 2014;20:386-92 \\ DOI: 10.12809/hkmj134066}

FKM Chan *, MB, BS

KC Cheng, MB, BS, FHKAM (Surgery)

YP Yeung, MB, BS, FHKAM (Surgery)

Department of Surgery, Kwong Wah Hospital, 25 Waterloo Road, Kowloon, Hong Kong

* Corresponding author: ckmfiona@hotmail.com

New knowledge added by this study

- Laparoscopic hepatectomies are feasible in our hospital where operative skills and techniques improved over time with experience.

Implications for clinical practice or policy

- Laparoscopic hepatectomies should be carried out in high-volume centres. Favourable results can be achieved with adequate experience, considering the steepness of the learning curve. The wide range of operative techniques for various types of laparoscopic hepatectomies implies that further exploration in training and learning curve effect is needed.

\section{Introduction}

Since its inception in 1992, laparoscopic liver resection (LLR) has been increasingly employed as the new alternative to open liver resection. ${ }^{1}$ Over 3000 cases of LLRs have been reported worldwide. ${ }^{2}$ The safety and efficacy of the procedure have been shown in recent evidence to be comparable with open surgery. The advantages of LLR over traditional open surgery are less analgesic requirements, less operative blood loss, shorter hospital stay, accompanied with a low operative mortality and morbidity of $0.3 \%$ and $11 \%$, respectively. Laparoscopic left lateral sectionectomies and wedge resections are now considered standardised operations performed routinely in dedicated centres. $^{7}$

Laparoscopic hepatectomy is considered to be a complicated laparoscopic procedure. The surgeon should be experienced in both laparoscopic and liver surgery. Most of the studies on the learning curve effect show improved outcome with experience. ${ }^{8-11}$ However, LLR is not a single procedure and the complexity of operation ranges from wedge resections to major hepatectomies involving anatomical resection of three or more segments. Experience in the complexity of procedure performed has not 
been adequately studied. In Kwong Wah Hospital, our experience with laparoscopic liver surgery commenced in 2006, and since then the procedure has been performed in an increasing number of patients. Here we report our experience with the first 100 cases of LLR and the learning curve effect through the series of cases.

\section{Methods}

All data including patient demographics, tumour characteristics, operative procedures, and outcomes were prospectively collected. All patients underwent chestradiographyandcontrastcomputed tomography (CT) of the abdomen. Magnetic resonance imaging and lipiodol arteriogram were performed in selected patients. Patients' preoperative liver function was assessed according to the Child-Pugh classification, ${ }^{12}$ and with indocyanine green retention test and CT volumetric analysis, if necessary. Patients were selected for laparoscopic liver surgery if they were medically fit for the major operation, Child-Pugh class A or B liver cirrhosis with adequate liver remnant after resection. Our centre adopted a less stringent criterion in terms of patient selection; hence, patients were included if LLR was considered technically feasible after evaluating patients' history of surgical operations, tumour size, and location. In the later years, indications were expanded to include resection of more benign pathologies and cholangiocarcinoma, wherein resection was anticipated to be more difficult. ${ }^{13,14}$

\section{Operative techniques}

All patients were operated on by specialist hepatobiliary surgeons with expertise in laparoscopic surgery. Hand-assisted or laparoscopic-assisted approaches were employed in the earlier period; however, the approach changed into total laparoscopy in the later period. Patient was put in Lloyd-Davis position for left hepatectomies and in semi-left lateral or left lateral position for right-sided lesion. Intra-operative laparoscopic ultrasound was used routinely. Five ports were used and placed according to tumour location. Parenchymal dissection was performed by Cavitron ultrasonic surgical aspirator (Valleylab Inc, Boulder [CO], US), Harmonic Scalpel (Harmonic ACE; Ethicon Endosurgery, Johnson \& Johnson, Langhorne [PA], US) or LigaSure (Valleylab). Methods employed for haemostasis included bipolar diathermy, metal clips, Hem-olok (Weck Surgical Instruments, Teleflex Medical, Durham [NC], US) or endovascular staplers; the Pringle manoeuvre was not used routinely. Specimen was put inside a plastic bag and retrieved via a Pfannenstiel incision if the specimen was large or by extension of one of the port sites if the specimen was small. Pneumoperitoneum was re-established after

\section{腹腔鏡肝臟切除手術：經驗100例手術後的分享} 陳嘉汶、鄭繼志、楊玉鵬

目的：分享於本院進行了 100 例腹腔鏡肝臟切除手術後的一些經驗和 學習曲線。

設計：病例系列的內部比較。

安排：香港一所分區醫院。

患者：本院自2006年起開始進行腹腔鏡肝臟切除術。從2006年3月至 2012 年 10 月期間所有曾接受腹腔鏡肝臟切除術的病例均被列入一個 前瞻性收集數據庫。從數據庫取出人口學資料和手術結果, 並把前期 (2006年3月至2010年5月) 和後期（2010年6月至2012年10月）的 手術結果進行了比較。

結果：2006年3月至2012年10月期間，於廣華醫院外科部共有98名 患者 (100例) 接受腹腔鏡肝臟切除術。他們分別為69名男性 ( $70 \%$ ) 和29名女性 $(30 \%)$; 年齡中位數為65歲。最後的病理診斷如下： 肝細胞癌（72例）、結直腸癌肝轉移（14例）、肝內膽管細胞癌（4 例 ）和良性病變（10例）。與前期相比，後期有較多解剖切除、肝大 部份切除, 以及更具挑戰性的解剖右路和後上病變的切除。然而, 兩 段時期的手術結果相若。

結論：隨著經驗的累積, 腹腔鏡肝臟切除越是可行。要注意的是, 各 種腹腔鏡肝臟切除手術須具不同程度的技術水平, 如可延續先前經 驗, 很快便可克服學習曲線。

specimen retrieval at a pressure of 6 to $8 \mathrm{~mm} \mathrm{Hg}$ to check for haemostasis. Tissue glue (Tisseel; Baxter, Vienna, Austria) was applied selectively. Abdominal drains were inserted as needed.

\section{Statistical analyses}

Patients who underwent laparoscopic hepatectomies were divided chronologically into two periods for comparison. Those performed from March 2006 to May 2010 were classified into the 'early group' while those performed from June 2010 to October 2012 were classified into the 'late group'. All data including patient demographics, operative and postoperative parameters were retrieved from a prospectively collected database. Operative parameters included operation type, conversion, operating time, blood loss, transfusion requirement, duration of Pringle manoeuvre, and intra-operative complications. The postoperative parameters included resection margin, staging, medical and surgical complications, length of hospital stay, and operative mortality. Complications were recorded and classified according to the Clavien-Dindo classification. ${ }^{15}$ Postoperative survival was measured using KaplanMeier estimates.

Statistical analyses were performed with the Statistical Package for the Social Sciences (Windows version 16.0; SPSS Inc, Chicago [IL], US). Numerical data were expressed as the median value. Mann- 
TABLE I. Summary of liver resections performed from March 2006 to October 2012

\begin{tabular}{lrcc}
\hline Total hepatectomies & Early $(\mathbf{n}=\mathbf{1 2 5})$ & Late $(\mathbf{n = 8 7 )}$ & P value \\
\hline Laparoscopic hepatectomies & $50 / 125(40 \%)$ & $50 / 87(58 \%)$ & 0.141 \\
Major hepatectomies & $10 / 50(20 \%)$ & $16 / 50(32 \%)$ & 0.171 \\
Anatomical resections & $25 / 50(50 \%)$ & $31 / 50(62 \%)$ & 0.108 \\
\hline
\end{tabular}

TABLE 2. Patient and tumour characteristics, and indications of laparoscopic liver resection

\begin{tabular}{|c|c|c|c|}
\hline \multirow[t]{2}{*}{ Characteristic/indication } & \multicolumn{2}{|c|}{ Data } & \multirow[t]{2}{*}{$P$ value } \\
\hline & Early $(n=50)$ & Late $(n=50)$ & \\
\hline \multicolumn{4}{|l|}{ Characteristic } \\
\hline Median age (years) & 65 & 65 & 0.78 \\
\hline Gender (M/F) & $37 / 13$ & $33 / 17$ & 0.38 \\
\hline \multicolumn{4}{|l|}{ Child-Pugh score } \\
\hline$A$ & 49 & 48 & 0.56 \\
\hline $\mathrm{B} / \mathrm{C}$ & 1 & 2 & \\
\hline Median (range) tumour size (cm) & $2.3(1-10.5)$ & $2.5(0.25-13)$ & 0.09 \\
\hline No. of tumours ${ }^{*}$ & & & 0.68 \\
\hline 1 & 42 & 42 & \\
\hline 2 & 2 & 1 & \\
\hline 3 & 2 & 0 & \\
\hline 4 & 2 & 2 & \\
\hline 5 & 1 & 1 & \\
\hline Cirrhosis on pathology & $28 / 50$ & $16 / 50$ & 0.016 \\
\hline \multicolumn{4}{|l|}{ Tumour location (segments) $\dagger$} \\
\hline Anterior-inferior (segment 1-6) & 40 & 46 & 0.01 \\
\hline Posterior-superior (segment 7-8) & 13 & 17 & 0.38 \\
\hline Segment 7 & 4 & 13 & 0.017 \\
\hline Indication of LLR & & & - \\
\hline Hepatocellular carcinoma & 40 & 32 & \\
\hline Cholangiocarcinoma & 0 & 4 & \\
\hline Colorectal liver metastasis & 7 & 7 & \\
\hline Benign & 3 & 7 & \\
\hline Recurrent pyogenic cholangitis & 1 & 3 & \\
\hline Haemangioma & 0 & 1 & \\
\hline Adenoma & 0 & 1 & \\
\hline Cirrhotic nodule & 2 & 0 & \\
\hline Bile duct hamartoma & 0 & 1 & \\
\hline Focal nodular hyperplasia & 0 & 1 & \\
\hline
\end{tabular}

Abbreviation: LLR = laparoscopic liver resections

* Data of one case in early group and four cases in late group are missing due to pathologies of recurrent pyogenic cholangitis and cholangiocarcinoma

+ Tumours located in the right lobe were counted in both anterior-inferior and posterior-superior categories

Whitney $U$ test was used for comparing continuous variables. Chi squared test and Fisher's exact test were used for comparing categorical variables. Statistical significance was set at a $\mathrm{P}$ value of less than 0.05 .

\section{Results}

From March 2006 to October 2012, our unit performed a total of 212 hepatectomies. A laparoscopic approach was employed in 98 patients. The proportion of LLRs performed increased from $40 \%$ in the early group to $58 \%$ in the late group. There was an increasing proportion of laparoscopic major hepatectomies and anatomical resections in the late group versus the early group (Table 1 ).

A total of 98 patients who underwent LLRs were recruited during this study period. There were $69(70 \%)$ male and 29 (30\%) female patients; the median age was 65 years. Of the 98 patients, two underwent a second LLR, giving a total of 100 LLRs. Some of these patients had previously undergone conventional hepatectomy. The Eastern Cooperative Oncology Group status was 0 for all patients. The demographic data and tumour characteristics of the two groups are shown in Table 2. There were significantly more patients with cirrhosis in the early group $(\mathrm{P}=0.016)$, and more patients had segment 7 tumour in the late group $(\mathrm{P}=0.017)$.

Indications for liver resection are shown in Table 2. Overall, $72 \%$ of LLRs were performed for hepatocellular carcinoma, whereas benign pathologies accounted for $10 \%$ of all LLRs. There was an increase in the number of LLRs performed for benign pathologies and cholangiocarcinomas in the late versus the early period. The types of resection performed are listed in Table 3. The proportion of anatomical resections increased from $50 \%$ in the early period to $62 \%$ in the late period, including predominantly right hepatectomies (6\% vs 16\%) and right posterior sectionectomies ( $2 \%$ vs $8 \%$ ). An increasing proportion of major hepatectomies, including right and left hepatectomies, as well as right posterior sectionectomies, were performed in the late period ( $20 \%$ vs $32 \%)$. In addition, more resections involving the posterosuperior segments (including segments 7 and 8) were performed in the late period (34\% vs $26 \%$ ); these are considered to be anatomically more difficult resections. Pure laparoscopic approach was employed in the majority of LLRs, and more LLRs were performed with a pure laparoscopic approach in the late period than in the early period ( $98 \%$ vs $88 \%$ ) [Table 3 ].

A number of procedures were performed alongside with LLRs. These included two laparoscopic colectomies, two closures of ileostomies, one hepaticojejunostomy, one small bowel resection, and three radiofrequency ablation-assisted LLRs.

Table 4 shows the intra-operative results, postoperative complications, status of margin involvement, and hospital stay. Conversion rates were higher in the late period than in the early period $(14 \%$ vs $2 \%)$ but did not reach statistical significance. Among the operations that required conversion to a standard approach $(n=8)$, three were 
due to haemorrhage, and the rest were due to poor exposure, dense adhesions with resultant small bowel injury, anatomical limitations at posterior segment, and doubtful tumour margin during resection. There was no mortality in the early group and one in the late group. Complications were classified according to the Clavien-Dindo classification and are shown in Table 4 . One patient in the early group who had situs inversus experienced complications in the form of bile leakage from a segment 4 branch after an anatomical right hepatectomy; this patient required laparotomy with T-tube insertion. One patient in the late group was found to have extensive bowel ischaemia on postoperative day 2 after a laparoscopic right hepatectomy; this patient required reoperation but did not survive. Two patients, one each from the early and late groups, developed bile leak postoperatively after laparoscopic right hepatectomies; they were managed with imageguided drainage and endobiliary stenting.

A subgroup analysis was conducted for patients receiving laparoscopic right hepatectomies. Between the early and late period, a total of 11 laparoscopic right hepatectomies were performed. Table 5 shows the peri-operative results of these patients. With increasing experience, the operating time, blood loss, transfusion rate and volume, as well as duration of hospital stay were significantly reduced.

The 2-year survival, according to KaplanMeier survival analysis, showed an overall survival of $89.1 \%$ in the early group versus $96.9 \%$ in the late group ( $\log$ rank $\mathrm{P}=0.593$; Fig). Since the majority of the study population were recruited after 2008, 5 -year survival data from this main bulk of patients were not available for this analysis.

\section{Discussion}

Laparoscopic hepatectomies are technically demanding. ${ }^{16,17}$ The difficulty lies in parenchymal transection with limited exposure and traction, thus requiring proficiency in both laparoscopic and liver surgery. The reproducibility and feasibility of the procedure have been questioned, preventing the procedure from being widely employed. Our current study demonstrated that, with growing experience, we could perform LLR safely, as demonstrated by the favourable overall outcome of LLR. The rates of overall mortality and major morbidity were $1 \%$ and $5 \%$, respectively. Reoperation was required in two (2\%) patients. For malignant indications, R0 resection rate (complete resection with no microscopic residual tumour) was 94\% (85/90). The overall results are in accordance with reports in the literature. ${ }^{2,5}$

Blood transfusion was required in $21 \%$ of our patients and the conversion rate was $8 \%$. We did not use the Pringle manoeuvre frequently because most of the bleeding occurred from hepatic veins.
TABLE 3. Types of laparoscopic liver resections

\begin{tabular}{|lccl}
\hline Item & Early $(\mathbf{n}=50)$ & Late $(\mathbf{n}=50)$ & P value \\
\hline Type of resection & & & \\
\hline Anatomical & $25(50 \%)$ & $31(62 \%)$ & 0.108 \\
\hline Left hepatectomy & $6(12 \%)$ & $4(8 \%)$ & 0.370 \\
\hline Right hepatectomy & $3(6 \%)$ & $8(16 \%)$ & 0.200 \\
\hline Left lateral sectionectomy & $7(14 \%)$ & $7(14 \%)$ & 1 \\
\hline Right posterior sectionectomy & $1(2 \%)$ & $4(8 \%)$ & 0.362 \\
\hline Bisegmentectomies & $1(2 \%)$ & $1(2 \%)$ & 1 \\
\hline Monosegmentectomy & $7(14 \%)$ & $7(14 \%)$ & 1 \\
\hline Non-anatomical & $25(50 \%)$ & $19(38 \%)$ & \\
\hline Additional procedures & 2 & 7 & \\
\hline Colectomy & 0 & 2 & \\
\hline Closure of ileostomy & 1 & 1 & \\
\hline Hepaticojejunostomy & 0 & 1 & \\
\hline Small bowel resection & 0 & 1 & \\
\hline Radiofrequency ablation & 1 & 2 & \\
\hline Laparoscopic approach & & & \\
\hline Pure laparoscopic & $44(88 \%)$ & $49(98 \%)$ & 0.140 \\
\hline Hand-assisted & $1(2 \%)$ & $0(0 \%)$ & \\
\hline Laparoscopic-assisted & $5(10 \%)$ & $1(2 \%)$ & \\
\hline
\end{tabular}

Among these eight patients requiring conversion, three quarters were related to bleeding from branches of the hepatic vein. We preferred a pure laparoscopic approach because the use of a hand port caused interference with laparoscopic trocars and instruments. ${ }^{18}$ It has been suggested that hand-assisted or hybrid approach offers speedy haemostasis but there is no solid evidence to support which single method is superior. We did not consider conversion to be a failure and hence, a higher conversion rate $(14 \%$ vs $2 \%, \mathrm{P}=0.06)$ was observed with a lower blood transfusion rate $(16 \%$ vs $26 \%, \mathrm{P}=0.22$ ) in the late versus the early period. No strict transfusion criteria were implemented. The decision of blood transfusion was mostly made by individual anaesthetist intra-operatively. Early in our series, we tended to initiate transfusion early because we anticipated bleeding during LLR to be more difficult to control. With gaining experience, transfusion was given more judiciously. Thus, with similar median blood loss, there was a trend towards lower transfusion rate in the late group as compared with the early group.

We further analysed the outcomes of the LLRs performed in the early and late periods. The overall outcome parameters were comparable with no significant learning curve effect observed. We observed a slight increase in operating time (263 vs 240 mins, $P=0.40$ ) and duration of hospital stay ( 6 vs 5 days, $\mathrm{P}=0.41$ ) during the later period, and we believe 
TABLE 4. Comparison between early and late laparoscopic hepatectomies and complications classified according to the ClavienDindo classification

\begin{tabular}{|c|c|c|c|}
\hline \multirow[t]{2}{*}{ Characteristic/indication } & \multicolumn{2}{|c|}{ No. or median (interquartile range) } & \multirow[t]{2}{*}{$P$ value } \\
\hline & Early $(n=50)$ & Late $(n=50)$ & \\
\hline \multicolumn{4}{|l|}{ Comparison between early and late periods } \\
\hline Blood loss (mL) & $325(95-1200)$ & $300(200-925)$ & 0.50 \\
\hline Transfusion volume $(\mathrm{mL})$ & $0(0-375)$ & $0(0-0)$ & 0.10 \\
\hline Transfusion & $13 / 50$ & $8 / 50$ & 0.22 \\
\hline Operating time (mins) & $240(167-323)$ & $263(168-426)$ & 0.40 \\
\hline Conversion to open surgery & $1 / 50$ & $7 / 50$ & 0.06 \\
\hline Positive margin & $3 / 47$ & $2 / 43$ & 0.646 \\
\hline Pringle manoeuvre & $2 / 50$ & $2 / 50$ & 1 \\
\hline Resection margin $(\mathrm{mm})$ & $5(0-20)$ & $7(0-30)$ & 0.50 \\
\hline Complications requiring reoperation & $1 / 50$ & $1 / 50$ & 1 \\
\hline Complications requiring radiological intervention & $1 / 50$ & $2 / 50$ & 0.56 \\
\hline Hospital stay (days) & $5(4-9)$ & $6(5-7.2)$ & 0.41 \\
\hline \multicolumn{4}{|c|}{ Complications classified according to the Clavien-Dindo classification } \\
\hline \multicolumn{4}{|l|}{1} \\
\hline Wound infection & 1 & 0 & 0.315 \\
\hline Pleural effusion & 2 & 1 & 0.558 \\
\hline Wound gapping & 1 & 0 & 0.315 \\
\hline \multicolumn{4}{|l|}{ II } \\
\hline Chest infection & 0 & 2 & 0.153 \\
\hline Acute myocardial infarction & 1 & 1 & 1 \\
\hline Arrhythmia & 0 & 4 & 0.041 \\
\hline Urinary tract infection & 0 & 1 & 0.315 \\
\hline \multicolumn{4}{|l|}{ III } \\
\hline \multicolumn{4}{|l|}{ IIla } \\
\hline Bile leak & 1 & 1 & 1 \\
\hline Upper gastro-intestinal bleed & 1 & 0 & 0.315 \\
\hline Intra-abdominal collection & 0 & 1 & 0.315 \\
\hline \multicolumn{4}{|l|}{$\mathrm{Illb}$} \\
\hline Bile leak & 1 & 0 & 0.315 \\
\hline \multicolumn{4}{|l|}{ IVa } \\
\hline Liver failure & 1 & 0 & 0.315 \\
\hline \multicolumn{4}{|l|}{$\mathrm{V}$} \\
\hline In-hospital mortality & 0 & 1 & 0.315 \\
\hline
\end{tabular}

that this was probably related to the increasing techniques of performing LLR. However, we believe number of laparoscopic major hepatectomies and that we are still on the learning curve for the more anatomical resections of right-sided lesions, as well difficult LLRs because the operative outcomes did as posterior segment LLRs performed in the later period.

With increasing experience in performing LLRs, we extended our indications of LLR from peripherally located tumours to posterosuperior lesions and from wedge resections to major resections, all reflecting an improvement in our not improve much. We managed to perform more anatomical resections with time in order to secure oncological safety. However, 5-year survival and recurrence results of our patients are not available for comparison between these two study groups.

The subject of learning curve effect of laparoscopic hepatectomy has been investigated 
TABLE 5. Comparison of laparoscopic right hepatectomies in the early and late period

\begin{tabular}{lccc}
\hline \multirow{2}{*}{ Item } & \multicolumn{2}{c}{ No. or median (interquartile range) } & \multirow{2}{*}{ P value } \\
\cline { 2 - 3 } & Early $(\mathbf{n = 3})$ & Late $(\mathbf{n}=\mathbf{8})$ & \\
\hline Blood loss $(\mathrm{mL})$ & $1500(1000-1800)$ & $450(220-875)$ & 0.030 \\
Transfusion volume $(\mathrm{mL})$ & $900(600-1200)$ & $0(0-600)$ & 0.033 \\
Transfusion & $3 / 3$ & $2 / 8$ & 0.026 \\
Operating time (mins) & $540(520-665)$ & $425(344-472)$ & 0.026 \\
Conversion to open surgery & $0 / 3$ & $1 / 8$ & 0.521 \\
Positive margin & $0 / 3$ & $1 / 8$ & 0.521 \\
Pringle manoeuvre & $1 / 3$ & $0 / 8$ & 0.087 \\
Resection margin (mm) & $1(1-2.3)$ & $5.5(0-15)$ & 0.280 \\
Complications requiring reoperation & $0 / 3$ & $1 / 8$ & 0.521 \\
Complications requiring radiological intervention & $1 / 3$ & $1 / 8$ & 0.425 \\
Hospital stay (days) & $20(16-35)$ & $7.5(6.25-10)$ & 0.002 \\
\hline
\end{tabular}

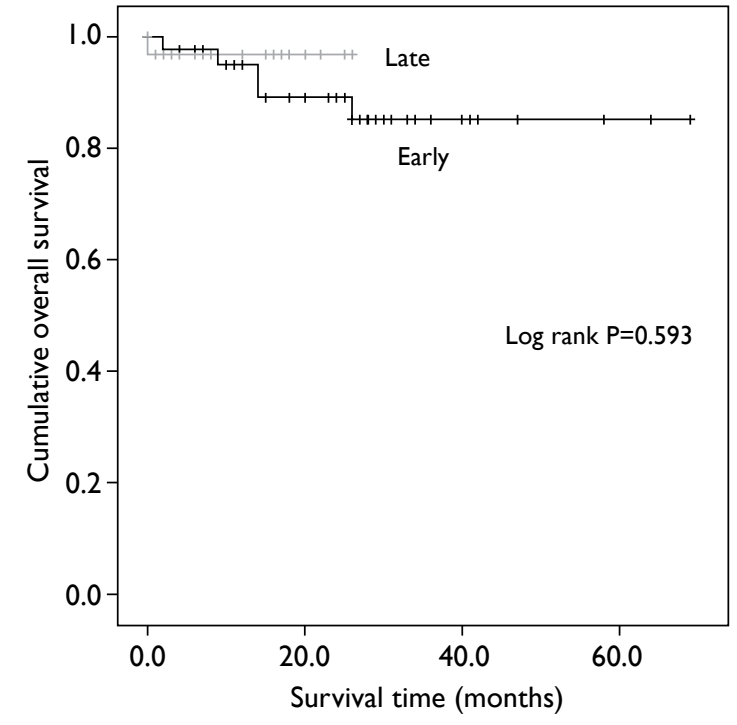

FIG. Kaplan-Meier estimates of overall survival of patients from the early and late groups

by several authors in the literature. Many studies attempted to identify the number of hepatectomies required to overcome the learning curve effect. ${ }^{8-11}$ The 12-year experience of Vigano et $\mathrm{al}^{9}$ demonstrated that after performing 60 consecutive cases of laparoscopic hepatectomies, operative outcomes in three consecutive periods in terms of conversion rate $(15.5 \%, 10.3 \%$, and $3.4 \% ; \mathrm{P}<0.05)$, operating time (210, 180, and 150 mins; $\mathrm{P}<0.05)$, blood loss (300, 200, and $200 \mathrm{~mL} ; \mathrm{P}<0.05)$, and morbidity (17.2\%, 22.4\%, and 3.4\%; $\mathrm{P}<0.05)$ improved. They reported a steady increase in the proportion of LLRs and a statistically significant increment in major and right hepatectomies in the later period of the study. The cumulative analysis of conversion rates in minor hepatectomies showed that at the 60th consecutive case, the conversion rate reached the average value and improved thereafter. A Korean group examined the results from their first 100 cases of laparoscopic liver surgery. ${ }^{8}$ Their mean operating time was 220 minutes and the overall morbidity was $11 \%$. They demonstrated a decrease in the volume of blood transfusion in the latter half of patients operated with a malignant pathology. Kluger et al $^{11}$ investigated the learning curve effect in laparoscopic major hepatectomy. Dividing their study results chronologically into three phases, they showed a steady increase in the proportion of major LLRs ( $1 \%$ vs $9 \%, \mathrm{P}<0.05)$ and malignant lesions being resected at a later stage in the study period. Median operating time $(150$ vs 210 mins, $\mathrm{P}<0.05)$, blood loss (200 vs $300 \mathrm{~mL}, \mathrm{P}<0.05)$, and clamping time $(20$ vs 45 mins, $\mathrm{P}<0.05)$ were significantly lower in the later study period. Morbidity rates also improved significantly with time ( $3 \%$ vs $17 \%, \mathrm{P}<0.05)$. Their group concluded that a learning curve existed for both the operator and the institution, and a highvolume environment enables overcoming of the learning curve. The latest experience in the attempt to identify a learning curve came from a UK group. ${ }^{10}$ Analysing their 37 LLRs, the researchers concluded that their results followed a learning curve whereby more complicated procedures could be performed in the latter part of their experience. They also emphasised the importance of achieving proficiency in laparoscopic hepatectomies via simulation and wet laboratories. From our experience, we agree that we could safely expand our indications from wedge resection of small tumours at anterior and 
superior liver segments to major resections and posterosuperior lesions. However, the technical demand and learning path for wedge resections are entirely different from those of anatomical hemihepatectomies or monosegmentectomies. The training for LLR and learning curve issue is still an important unresolved topic that needs to be investigated further.

\section{Conclusion}

Laparoscopic hepatectomies are feasible and safe with favourable patient outcomes. A learning curve is present and could be overcome with increasing experience. However, the long-term outcomes associated with the procedure require further study with longer follow-up.

\section{References}

1. Gagner M, Rheault M, Dubuc J. Laparoscopic partial hepatectomy for liver tumor [abstract]. Surg Endosc 1992;6:99.

2. Nguyen KT, Gamblin TC, Geller DA. World review of laparoscopic liver resection-2,804 patients. Ann Surg 2009;250:831-41.

3. Buell JF, Cherqui D, Geller DA, et al. The international position on laparoscopic liver surgery: the Louisville Statement, 2008. Ann Surg 2009;250:825-30.

4. Simillis C, Constantinides VA, Tekkis PP, et al. Laparoscopic versus open hepatic resections for benign and malignant neoplasms-a meta-analysis. Surgery 2007;141:203-11.

5. Koffron AJ, Auffenberg G, Kung R, Abecassis M. Evaluation of 300 minimally invasive liver resections at a single institution: less is more. Ann Surg 2007;246:385-92.

6. Croome KP, Yamashita MH. Laparoscopic vs open hepatic resection for benign and malignant tumors: an updated meta-analysis. Arch Surg 2010;145:1109-18.

7. Chang S, Laurent A, Tayar C, Karoui M, Cherqui D.
Laparoscopy as a routine approach for left lateral sectionectomy. Br J Surg 2007;94:58-63.

8. Lee MR, Kim YH, Roh YH, et al. Lessons learned from 100 initial cases of laparoscopic liver surgery. J Korean Surg Soc 2011;80:334-41.

9. Vigano L, Laurent A, Tayar C, Tomatis M, Ponti A, Cherqui D. The learning curve in laparoscopic liver resection: improved feasibility and reproducibility. Ann Surg 2009;250:772-82.

10. Robinson SM, Hui KY, Amer A, Manas DM, White SA. Laparoscopic liver resection: is there a learning curve? Dig Surg 2012;29:62-9.

11. Kluger MD, Vigano L, Barroso R, Cherqui D. The learning curve in laparoscopic major liver resection. J Hepatobiliary Pancreat Sci 2013;20:131-6.

12. Pugh RN, Murray-Lyon IM, Dawson JL, Pietroni MC Williams R. Transection of the oesophagus for bleeding oesophageal varices. Br J Surg 1973;60:646-9.

13. Cheng KC, Yeung YP, Hui J, Ho KM, Yip AW. Laparoscopic resection of hepatocellular carcinoma at segment 7: the posterior approach to anatomic resection. Surg Endosc 2011;25:3437.

14. Yeung YP. Laparoscopic anatomic monosegmentectomy of hepatocellular carcinoma of the right hepatic lobe. Surg Laparosc Endosc Percutan Tech 2012;22:e259-62.

15. Dindo D, Demartines N, Clavien PA. Classification of surgical complications: a new proposal with evaluation in a cohort of 6336 patients and results of a survey. Ann Surg 2004;240:205-13.

16. Buell JF, Thomas MJ, Doty TC, et al. An initial experience and evolution of laparoscopic hepatic resectional surgery. Surgery 2004;136:804-11.

17. Morino M, Morra I, Rosso E, Miglietta C, Garrone C. Laparoscopic vs open hepatic resection: a comparative study. Surg Endosc 2003;17:1914-8.

18. Cardinal JS, Reddy SK, Tsung A, Marsh JW, Geller DA. Laparoscopic major hepatectomy: pure laparoscopic approach versus hand-assisted technique. J Hepatobiliary Pancreat Sci 2013;20:114-9. 